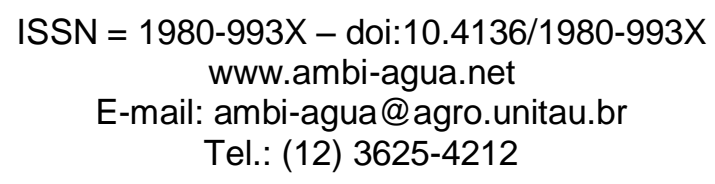

\title{
Concentración de clorofila-a y límite de zona fótica en el embalse Río Tercero (Argentina) utilizando imágenes del satélite CBERS-2B
}

\author{
(http://dx.doi.org/10.4136/ambi-agua.847)
}

\author{
Matias Bonansea ${ }^{1}$; Claudia Ledesma ${ }^{2}$; \\ Claudia Rodriguez ${ }^{3}$; Angel Ramon Sanchez Delgado ${ }^{4}$ \\ Becario Conicet. Universidad Nacional de Rio Cuarto \\ ${ }^{1}$ Becario Conicet. Universidad Nacional de Rio Cuarto, Ecología. Facultad de Agronomía y Veterinaria, \\ Córdoba, Argentina, e-mail: mbonansea@ayv.unrc.edu.ar, \\ ${ }^{2}$ Universidad Nacional de Rio Cuarto, Matemática y Bioestadística, Córdoba, Argentina, \\ e-mail: cledesma@ayv.unrc.edu.ar, \\ ${ }^{3}$ Universidad Nacional de Rio Cuarto, Ecología. Facultad de Agronomia y Veterinária e Programa de Pós- \\ graduação em Ciência, Tecnologia e Inovação Agropecuária; Córdoba, Argentina, \\ e-mail: crodriguez@ayv.unrc.edu.ar, \\ ${ }^{4}$ Universidade Federal Rural do Rio de Janeiro, Programa de Pós-graduação em Ciência, Tecnologia e Inovação \\ Agropecuária; Rio de Janeiro, RJ, Brasil, \\ e-mail: asanchez@ufrrj.br
}

\section{RESUMEN}

Las imágenes satelitales provistas por sensores remotos representan una herramienta importante en el monitoreo, control y gestión de los recursos hídricos. El objetivo del siguiente trabajo fue modelar la distribución espacial de la concentración de clorofila-a y el límite de la zona fótica en el embalse Río Tercero (Córdoba-Argentina), utilizando imágenes del satélite CBERS-2B y un sistema de información geográfica (SIG). Fueron seleccionados 15 sitios de muestreo en donde se midieron parámetros físicos, químicos y biológicos, durante el otoño de 2008. Utilizando una imagen georreferenciada del sensor CBERS-2B y por medio del análisis de componentes principales (ACP), se lograron identificar asociaciones entre variables y valores de reflectancia de las bandas de dicho satélite. En base a estas asociaciones y con modelos de regresión múltiples, se crearon las respuestas estimadas para conocer la distribución espacial de las variables, concentración de clorofila-a $\left(\mathrm{R}^{2}=0,73\right)$ y límite de zona fótica $\left(\mathrm{R}^{2}=0,78\right)$ en todo el reservorio. Podemos concluir que existe una correlación negativa entre la concentración de clorofila-a y la transparencia de la agua en el embalse Rio Tercero; como también que el sensor utilizado, permite evaluar la calidad del agua en un tiempo relativamente corto.

Palabras llaves: sensores remotos, recursos hídricos, ACP.

\section{Concentração de clorofila-a e limite de zona fótica no reservatório Rio Tercero (Argentina) utilizando imagens do satélite CBERS-2B}

\section{RESUMO}

As imagens de satélites com sensores remotos representam uma ferramenta importante no monitoramento, controle e gestão dos recursos hídricos. O objetivo do seguinte trabalho foi modelar a distribuição espacial da concentração de clorofila-a e o limite da zona fótica no reservatório Rio Tercero (Córdoba-Argentina), utilizando imagens do satélite CBERS-2B e um sistema de informação geográfica (SIG). Foram selecionados 15 sítios do reservatório onde foram medidos parâmetros físicos, químicos e biológicos no outono de 2008. Utilizando 
uma imagem georreferenciada do sensor CBERS-2B e com base na análise de componentes principais (ACP), identificou-se associações entre variáveis e valores de reflectância das bandas do satélite. Com base nessas associações e com modelos de regressão múltiplas, alcançaram-se as respostas estimadas para se conhecer a distribuição espacial das variáveis: concentração de clorofila-a $\left(\mathrm{R}^{2}=0,73\right)$ e limite de zona fótica $\left(\mathrm{R}^{2}=0,78\right)$ em tudo o reservatório. Pôde-se concluir que existe uma corelação negativa entre a concentração de clorofila-a e a transparência da água no reservatório Rio Tercero; assim como que o sensor utilizado permite a avaliação da qualidade da água em tempo relativamente curto.

Palavras-chave: sensores remotos, recursos hídricos, ACP.

\title{
Concentration of chlorhophyll-a and the limit of the photic zone in the Third River reservoir (Córdoba-Argentina), using images from CBERS-2B satellite
}

\begin{abstract}
The satellite images provided by remote sensors represent an important tool for monitoring, controlling and administering water resources. The aim of this work was to model the spatial distribution of the concentration of chlorhophyll-a and the limit of the photic zone in the Rio Tercero reservoir (Córdoba-Argentina), using images from CBERS-2B satellite and a geographical information system (SIG). We selected 15 samples places wherefrom we measured physical, chemical and biological parameters during the fall of 2008. By using a georeferenced image from sensor CBERS-2B and performing an analysis of the principal components (ACP), we were able to identify associations between variables and reflectance values of the satellite bands. Based on these associations and with simple regression models, we were able to know the spatial distribution of the variables: concentration of chlorophyll-a $\left(\mathrm{R}^{2}=0,73\right)$ and the limit of the photic zone $\left(\mathrm{R}^{2}=0,78\right)$ in the reservoir as a whole. We may conclude thata there exists a negative correlation between the concentration of chlorophyll-a and the water transparency in reservoir Rio Tercero, as well as that the sensor used allows us to evaluate the quality of the water in a relative short time.
\end{abstract}

Keywords: remote sensors, water resources, ACP.

\section{INTRODUCIÓN}

Históricamente, la preocupación de los países por contar con agua suficiente en cantidad y calidad para sus diferentes actividades es cada vez mayor. Los lagos y embalses proveen el agua para el consumo humano y permiten realizar una serie de funciones ambientales sumamente valiosas. Sin embargo, estos sistemas están expuestos a la degradación ambiental, siendo la eutroficación uno de los problemas más comunes que producen impactos ecológicos, sanitarios y económicos, significativamente negativos a escala local y regional (Rodríguez, 1997). Si bien la eutroficación es parte de un proceso natural de envejecimiento de los lagos, que ocurre en forma lenta e independientemente de la actividad del hombre, la creciente urbanización, el desarrollo agrícola y energético, aceleran este proceso, acortando la vida útil del cuerpo de agua. De esta manera, se genera una "eutroficación artificial o cultural", que es mucho más acelerada y peligrosa que la natural. La importancia que tiene la detección y valorización de las fuentes de nutrientes que ingresan al sistema (principalmente fósforo y nitrógeno), es que a partir de sus análisis, podemos planificar esfuerzos futuros para mantener la calidad del agua. 
BONANSEA, M.; LEDESMA, C.; RODRIGUEZ, C.; DELGADO, A. S. R. Concentración de clorofila-a y límite de zona fótica en el embalse Río Tercero (Argentina) utilizando imágenes del satélite CBERS-2B. AmbiAgua, Taubaté, v. 7, n. 3, p. 61-71, 2012. (http://dx.doi.org/10.4136/ambi-agua.847)

La literatura muestra que a la hora de generar un programa para el análisis de la calidad del agua en un reservorio acuático, los parámetros bio-físicos comúnmente seleccionados son la concentración de clorofila-a, los sedimentos en suspensión y la transparencia del agua (Zhu et al., 2005; Gonzalez et al., 2011). La transparencia del agua, es expresada como el límite de la zona fótica (z-fot). Margalef (2002) define el límite de la zona fótica como la profundidad en la cual la intensidad de la luz queda reducida a un $1 \%$ de la que ha penetrado en la superficie; constituyendo un límite por debajo del cual no queda lugar para los procesos de fotosíntesis. Entre las formas de medir el fitoplancton presente en un cuerpo de agua, la más utilizada es la concentración de clorofila-a, expresada como los pigmentos fotosintéticos por unidad de volumen. Los crecimientos masivos de algas y cianbacterias que se producen por eutroficación, pueden ocasionar mortandades de animales y producir malestares gastrointestinales en los seres humanos, debido a la producción de cianotoxinas (Vincent et al., 2004).

De esta manera, conocer las concentraciones existentes de este compuesto en el agua, así como la profundidad máxima en la cual las comunidades algares pueden subsistir, son de suma importancia en el control y gestión de lagos y embalses (Martini et al., 2006). Los análisis limnológicos se basan en muestras "in sintu" realizados a partir de un número limitado de estaciones, siendo la productividad primaria computada por la extrapolación de medidas puntuales. Muchas veces, tales metodologías no permiten evaluar con precisión la variabilidad espacial y temporal del sistema en estudio. Estas limitaciones metodológicas pueden ser suprimidas con la utilización de sensores remotos en estudios de sistemas acuáticos (Felix 1993; Cestari et al., 1996; Brunkow 2004; Tundisi, 2005; Tundisi et al., 2006; Breunig et al., 2007; Corazza, 2010; Wachholz, 2012). De acuerdo con Novo (1998), sensoriamento remoto es la utilización de sensores para la adquisición de informaciones sobre objetos y fenómenos, sin que haya contacto directo entre ellos. Son equipamientos capaces de colectar energía proveniente del objeto, convirtiéndola en señal adecuadamente registrable para la extracción de informaciones.

El procesamiento de imágenes satelitales provistas por sensores remotos, junto a un sistemas de información geográfica (SIG) y técnicas de modelación, pueden ser utilizadas para evaluar espacial y temporalmente la calidad del agua en una superficie, mediante el estudio de algunos parámetros con tiempo y respuesta relativamente cortos (Sass et al., 2007). Pereira Filho et al. (2011) encontraron una relación de la clorofila-a con la banda verde del sensor Landsat 5 TM en aguas del reservatorio de Passo Real, en Rio Grande del Sur, Brasil; en cuanto, Santos y Dubreuil (2009) consiguieron estimar el material en suspensión a través de las bandas roja e infra-rojo, para el reservatorio de Manso Grosso, Brasil. Rudorft et al. (2007) identificaron una relación entre los datos de los sólidos en suspensión y la clorofila-a, con datos espectrales del sensor Hyperion/E01 en aguas amazónicas.

En mayo del 2010, el Instituto Nacional de Pesquisas Espaciales del Brasil (INPE) anunció el final de la misión del satélite Sino-Brasileiro CBERS-2B (Brasil-China), pero no del programa CBERS; que representa una pieza fundamental para el sector técnico-científico espacial, así como de suma importancia para el Brasil se mantener dentro del selecto grupo de países con tecnología de sensores remotos. Prueba de eso son las renovaciones bilaterales ya realizadas para los CBERS-3 y 4. La familia de satélites de sensoramiento remoto CBERS, le ha dado al Brasil avances científicos, como también una tecnología valiosa para el seguimiento del nuevo código forestal; un ejemplo de eso, es el uso de imágenes para el control de la Amazona, el monitoreo de los recursos hídricos, el crecimiento urbano, la ocupación de la tierra y muchas otras (Santos et al., 2005). El satélite CBERS-2B, contaba con una cámara de alta resolución CCD (Couple Charged Device) que presenta 5 bandas espectrales, las cuales se reparten entre la franja visible e infra-rojo cercano $(450-520 \mathrm{~nm}$; 
BONANSEA, M.; LEDESMA, C.; RODRIGUEZ, C.; DELGADO, A. S. R. Concentración de clorofila-a y límite de zona fótica en el embalse Río Tercero (Argentina) utilizando imágenes del satélite CBERS-2B. AmbiAgua, Taubaté, v. 7, n. 3, p. 61-71, 2012. (http://dx.doi.org/10.4136/ambi-agua.847)

520-590 nm; 630-690 nm; 770-890 nm; 510-730 nm). Una resolución espacial de $20 \mathrm{~m}$ y una resolución temporal de 26 días (Lino et al., 2000; Todt et al., 2006).

En Argentina, las políticas públicas de gestión aplicadas a recursos hídricos carecen de visión, quizás por no establecer planes a largo plazo. Con respecto a la provincia de Córdoba, el estado trófico de diques y embalses, varían entre mesotróficos y eutróficos con altas cargas de materia orgánica (Rodríguez et al., 2006). La mayoría de ellos están altamente influenciados por la agricultura, ganadería, actividad minera, erosión del suelo y descarga de efluentes domésticos e industriales no tratados. Esta problemática no escapa de la observada en el embalse de Rio Tercero en los últimos cuatro años.

Durante el otoño del 2008, realizamos una experiencia de campo y numérica para la determinación de la distribución espacial de la concentración de clorofila-a y el límite de la zona fótica del embalse Río Tercero (Córdoba-Argentina), utilizando imágenes del satélite CBERS-2B; que a pesar de ya no estar en órbita, hallamos interesante presentar una más de sus múltiples contribuciones. En este artículo, modelamos y analizamos la distribución espacial de la concentración de clorofila-a y el límite de la zona fótica del embalse Río Tercero, utilizando imágenes del satélite CBERS-2B, SIG y modelos estadísticos de regresión; como también, algunas comparaciones con los resultados obtenidos en escenarios brasileros que usaron sensoramiento remoto.

\section{MATERIAL Y MÉTODOS}

\section{1. Área de estudio}

El embalse Río Tercero está localizado en el centro de la provincia de Córdoba y abarca una superficie de 4.600 ha, entre los $32^{\circ} 00^{\prime}$ y $32^{\circ} 30^{\prime}$ de latitud sur y los $64^{0} 24^{\prime}$ y $64^{0} 57^{\prime}$ de longitud oeste. Su profundidad media es de $12 \mathrm{~m}$ (máxima $46 \mathrm{~m}$ ) y su tiempo de residencia de 0,84 años (Boltovskoy y Foggetta, 1985; Mariazzi et al., 1992); siendo el cuerpo artificial de agua más grande de la provincia. En las costas de esta represa se encuentran las localidades de Villa del Dique y Villa Rumipal, que aprovechan este recurso para consumo humano, animal, generación de energía eléctrica, riego y actividades recreacionales (náutica y pesca deportiva), como es mostrado en la Figura 1.

\subsection{Toma de muestras}

Se realizó un muestreo durante el otoño de 2008 en fecha coincidente con el paso del satélite CBERS-2B por la zona de estudio. Se seleccionaron 15 sitios de muestreo (Figura 1), en los que se recolectaron muestras a $20 \mathrm{~cm}$ de profundidad. In situ se determinaron las coordenadas de ubicación geográfica con GPS; temperatura del agua, $\mathrm{pH}$, oxígeno disuelto, conductividad y la profundidad del disco de Secchi, que fue utilizada para el cálculo del límite de la zona fótica, definido como el producto entre la profundidad del disco de Secchi y el coeficiente de 2,5 (Ryding y Rast, 1992). En el laboratorio se determinó la concentración de clorofila-a, fósforo y nitrógeno total mediante espectrofotometría. Los lineamientos para la metodología de toma de muestra, almacenamiento conservación y técnicas analíticas se tomaron de APHA et al. (2000).

\subsection{Procesamiento de imágenes}

Se utilizó la imagen del satélite CBERS-2B (correspondiente al 27 de abril de 2008), cedida sin ningún costo, por el Instituto Nacional de Pesquisas Espaciales del Brasil (INPE). Para el análisis, procesamiento e interpretación de la misma se utilizó el software ENVI 3.5 (Versión 2001), desarrollado por ESRI (2001). Se georreferenció la imagen con un RMS (Error Medio Cuadrado) global de 0,84 pixel (20 metros/pixel). 


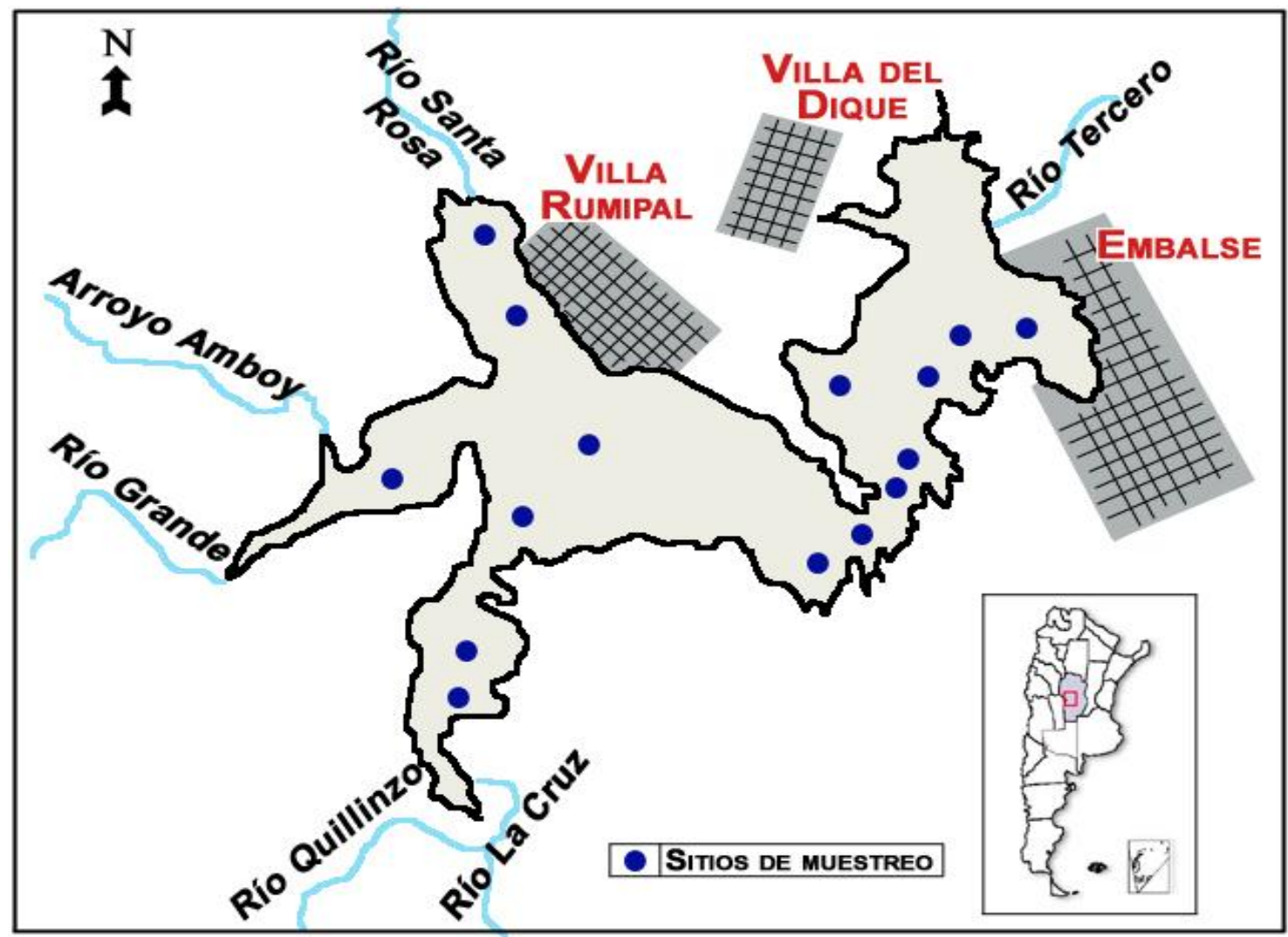

Figura 1: Ubicación de la zona de estudio y sitios de muestreo.

\subsection{Metodología}

Se construyeron los modelos de regresión múltiple para las variables cl-a y z-fot. Respecto a cl-a, se relacionaron las características espectrales de dicho parámetro y una combinación de las bandas 2 (b2) $(0,52-0,59 \mu \mathrm{m})$ y 3 (b3) $(0,63-0,69 \mu \mathrm{m})$ del satélite CBERS$2 \mathrm{~B}$, generando la siguiente respuesta:

$$
c l-a=32,71 * b 2+0,45 * b 3-45,02
$$

Considerando el coeficiente del parámetro Z-fót como variable regresora a los niveles digitales de las bandas $1(0,45-0,52 \mu \mathrm{m})(\mathrm{b} 1)$ y $4(0,77-0,89 \mu \mathrm{m})(\mathrm{b} 4)$, obtuvimos a función respuesta:

$$
z-f o t=0,01 * b 1-1,02 * b 4+40,96
$$

El valor del coeficiente de determinación fue $\mathrm{R}^{2}=0,78$; siendo no significativo para la banda 1 (p>0,05). Con el Software Estadístico InfoStat Profesional (Versión 2009), se realizó un Análisis de Componentes Principales (ACP), que fue utilizado para observar la variabilidad e identificar asociaciones entre los parámetros medidos en el embalse y los datos de reflectancia de las bandas del satélite CBERS-2B.

\subsection{Mapas de distribución}

Para obtener los mapas de distribución de las variables cl-a y z-fot del embalse Río Tercero, se generó una máscara del cuerpo de agua, sobre la cual se aplicaron las respuestas estimadas de las variables cl-a y z-fot. De esta manera se lograron predecir valores de dichos parámetros en toda la superficie del cuerpo de agua, permitiendo estimar variaciones espaciales. 
BONANSEA, M.; LEDESMA, C.; RODRIGUEZ, C.; DELGADO, A. S. R. Concentración de clorofila-a y límite de zona fótica en el embalse Río Tercero (Argentina) utilizando imágenes del satélite CBERS-2B. AmbiAgua, Taubaté, v. 7, n. 3, p. 61-71, 2012. (http://dx.doi.org/10.4136/ambi-agua.847)

\section{RESULTADOS Y DISCUSIÓN}

A continuación se describen los valores medios y el rango de los parámetros: Temperatura, pH, Oxígeno Disuelto, Conductividad, Zona Fótica, Clorofila-a, Nitrógeno Total y Fósforo Total; medidos en el embalse Río Tercero (Córdoba, Argentina) durante el otoño del 2008 (Tabla1).

Tabla 1. Parámetros: Temperatura (T), pH, Oxigeno Disuelto (OD), Conductividad (Cond.), Zona Fótica (ZF), Clorofila-a (Cl-a), Nitrógeno Total (NT), e Fósforo Total (FT); medios, mínimos y máximos, medidos en el embalse Río Tercero durante un muestreo realizado en otoño de 2008.

\begin{tabular}{l|llllllll}
\hline Variable & $\begin{array}{l}\mathbf{T} \\
{ }^{\mathbf{}} \mathbf{C}\end{array}$ & $\mathbf{p H}$ & $\begin{array}{l}\mathbf{O D} \\
\mathbf{m g} / \mathbf{L}\end{array}$ & $\begin{array}{l}\mathbf{C o n d} \\
\mathbf{m S} / \mathbf{c m}\end{array}$ & $\begin{array}{l}\mathbf{Z F} \\
\mathbf{M}\end{array}$ & $\begin{array}{l}\mathbf{C l - a} \\
\mathbf{m g} / \mathbf{L}\end{array}$ & $\begin{array}{l}\mathbf{N ~ T} \\
\mathbf{m g} / \mathbf{L}\end{array}$ & $\begin{array}{l}\mathbf{F} \mathbf{T} \\
\mathbf{m g} / \mathbf{L}\end{array}$ \\
\hline Medio & 21,4 & 7,8 & 10,9 & 1,45 & 6,8 & 24,0 & 1,2 & 0,013 \\
Mínimo & 20,3 & 6,8 & 9,3 & 1,40 & 3,8 & 5,4 & 0,9 & 0,012 \\
Máximo & 25,5 & 8,6 & 13,5 & 1,49 & 10,0 & 49,8 & 1,5 & 0,013 \\
\hline
\end{tabular}

En este período se observó una temperatura media de $21,4{ }^{\circ} \mathrm{C}$; con un valor mínimo y máximo de $20,3{ }^{\circ} \mathrm{C}$ y $25,5^{\circ} \mathrm{C}$ respectivamente, sin diferencias significativas. Respecto a los sitios de muestreo, los valores de temperatura más altos correspondieron a la salida de agua del canal de enfriamiento de la central nuclear, que utiliza $120.000 \mathrm{~m} 3 / \mathrm{h}$ de las aguas de este lago como refrigerante del reactor.

Durante la misma estación (otoño) del año 2009, se registraron temperaturas medias similares en el escenario de la Usina Hidroeléctrica Doña Francisca (UHE-Dona Francisca) (RS-Brasil) (Corazza, 2010) y un año antes (2007); en la Represa de Paraibuna, SP-Brasil (Días et al., 2007), a diferentes niveles de profundidad (0,5 m; $5 \mathrm{~m}$ y $10 \mathrm{~m})$, se observó una variación entre $20^{\circ} \mathrm{C}$ y $22^{\circ} \mathrm{C}$.

Los criterios de protección a la vida acuática fijan la variable $\mathrm{pH}$ (potencial hidrogenito) entre 6 y 9. El pH tiene influencia en diversos equilibrios químicos que ocurren naturalmente durante el tratamiento de aguas. En los ecosistemas acuáticos, posee efectos directos sobre la fisiología de diversas especies e indirectos en relación a la precipitación de elementos químicos tóxicos con metales pesados. También pode ejercer algún efecto en las salubridades de los nutrientes. La media del pH encontrado en el embalse Rio Tercero fue de 7,8; con un rango de 6,8 y 8,6 . No se encontró una tendencia del perfil multivariado de esta variable, ni un sitio de muestreo con características especiales.

La media del pH hallado en la UHE-Doña Francisca fue de 6,9; con un rango de 5,5 y 8,7; en cuanto que en el escenario de la Represa de Paraibuna se encontró una variación entre 5,93 y 7,08 .

La variable oxigeno disuelto (OD) presentó un rango de 9,3 a 13,5 mg/L con una media de 10,9 mg/L. A lo largo del tiempo, se observó una disminución en la concentración de OD que no sería significativa. Aunque no hubo una tendencia entre los sitios de muestreo, ya que los valores de OD varían entre una fecha y la siguiente, se advirtieron grandes desvíos entre los sitios y sus respectivas medias. Para obtener una conclusión más certera de esta variable, se recomendaría generar un gradiente vertical de concentración de oxígeno para conocer su comportamiento en todo el embalse. En la Represa de Paraibuna, el OD varió entre 6,35 y $8,52 \mathrm{mg} / \mathrm{L}$.

La concentración media del fósforo total (FT) encontrada en el embalse fue de 0,013 $\mathrm{mg} / \mathrm{L}$, con tendencia a aumentar a lo largo del tiempo. Esta condición podría deberse a la 
fuerte actividad antrópica que se realizan en algunas zonas del embalse (recreación), sumado con las descargas de efluentes no tratados. No se descarta que en un futuro se observen florecimientos de algas en estos sitios, lo que podría generar una serie de acontecimientos negativos para el funcionamiento del embalse. Siguiendo la clasificación de ITAIPU, el embalse Rio Tercero se encontraba (para la fecha), con una calidad de agua poco degradada. Ya en relación al nitrógeno total (NT), se observó una media de 1,2 $\mathrm{mg} / \mathrm{L}$ y un rango comprendido entre 0,9 y $1,5 \mathrm{mg} / \mathrm{L}$. Esta variable no presentó una tendencia muy marcada a lo largo del tiempo, aunque si se pudo registrar un leve aumento. Al igual que el FT, las máximas concentraciones se hallaron en sitios con alta actividad antrópica.

En relación a la clorofila-a, la concentración media fue de $24 \mathrm{mg} / \mathrm{L}$, en un rango amplio de 5,4 a 49,8 mg/L. Esta variable aumentó a lo largo del tiempo. Considerando que la clorofila-a depende de la concentración de nutrientes (FT y NT), penetración de la luz y temperatura del agua, es posible que estos aumentos se deban a los aumentos hallados en las concentraciones del FT. Entre los sitios de muestreo, se observó que las concentraciones más altas se presentaron en el canal de enfriamiento de la central nuclear y en el murallón del embalse. En el primer caso, el incremento de clorofila-a pudo deberse a la alta temperatura que posee el agua en este sitio, favoreciendo la proliferación de algas. En el segundo caso, podría ser el producto de la alta concentración de nutrientes y de los vientos que generan una deriva del fitoplancton hacia la zona en cuestión. Los vientos predominantes en el embalse Rio Tercero provienen del sector suroeste.

En la UHE-Doña Francisca, la elevada concentración de clorofila-a fue atribuida a la transparencia del agua y a las condiciones ambientales, ya que el reservatorio se encuentra en un valle encajado en un entorno dominado por una cobertura forestal.

En relación a la conductividad, se obtuvo una media de $1,45 \mathrm{mS} / \mathrm{cm}$, con un valor mínimo de $1,40 \mathrm{mS} / \mathrm{cm}$ y un valor máximo de $1,49 \mathrm{mS} / \mathrm{cm}$. También, el valor medio de la zona fótica fue de $6,8 \mathrm{~m}$ y un rango entre 3,8 y $10 \mathrm{~m}$.

A partir del análisis multivariado de componentes principales (ACP) y usan todos componentes que explican el 74,5\% de la variabilidad total de los datos, se generó un grafico biplot (Figura 2), donde se observó correlación positiva entre la variable cl-a y los datos de reflectancia de las bandas 2 y 3 del satélite CBERS-2B, mientras que la variable $\mathrm{z}$-fot se correlacionó en forma positiva con la bandal y negativamente con la banda 4 de dicho satélite.

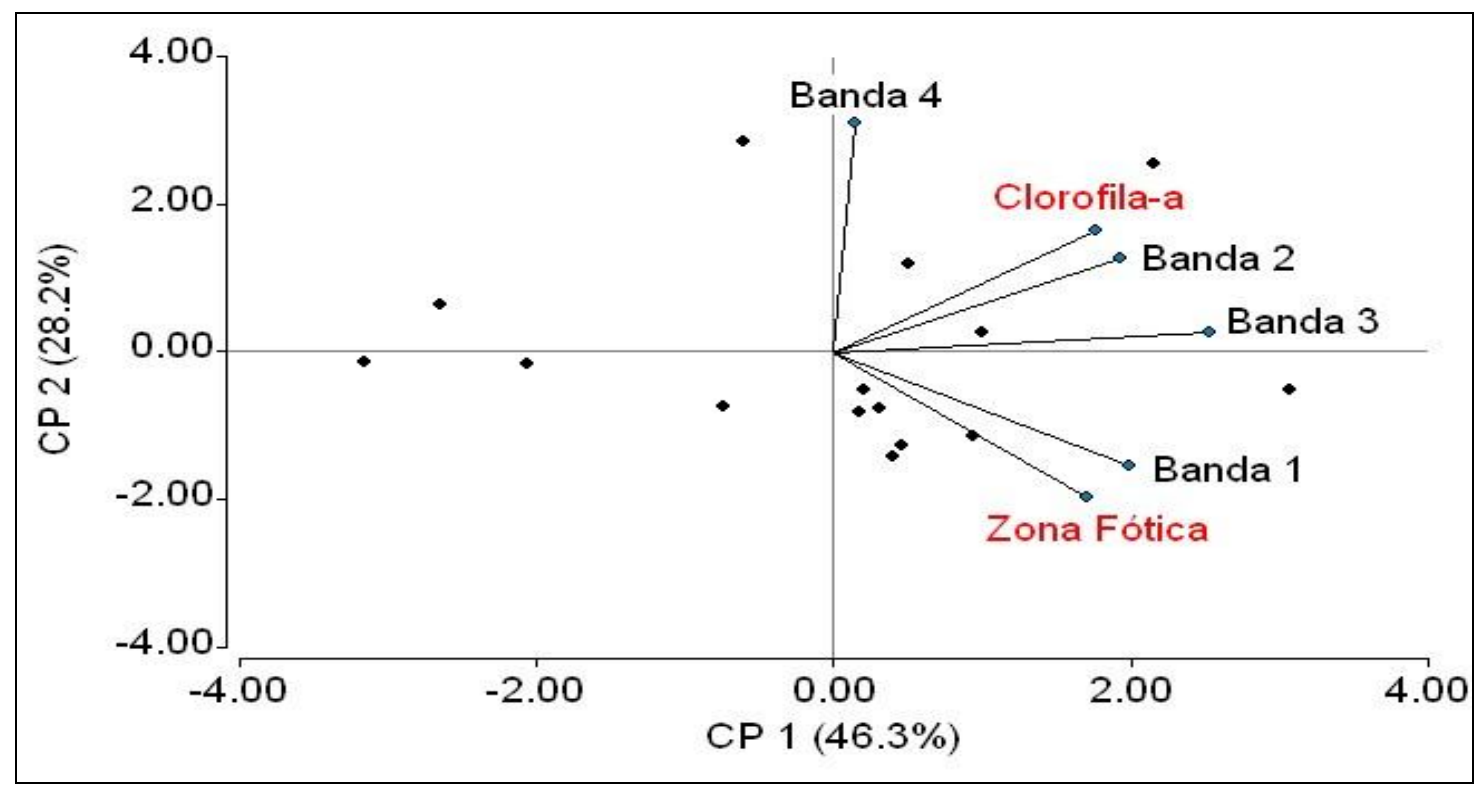

Figura 2. Diagrama de Componentes Principales (CP1/CP2). 


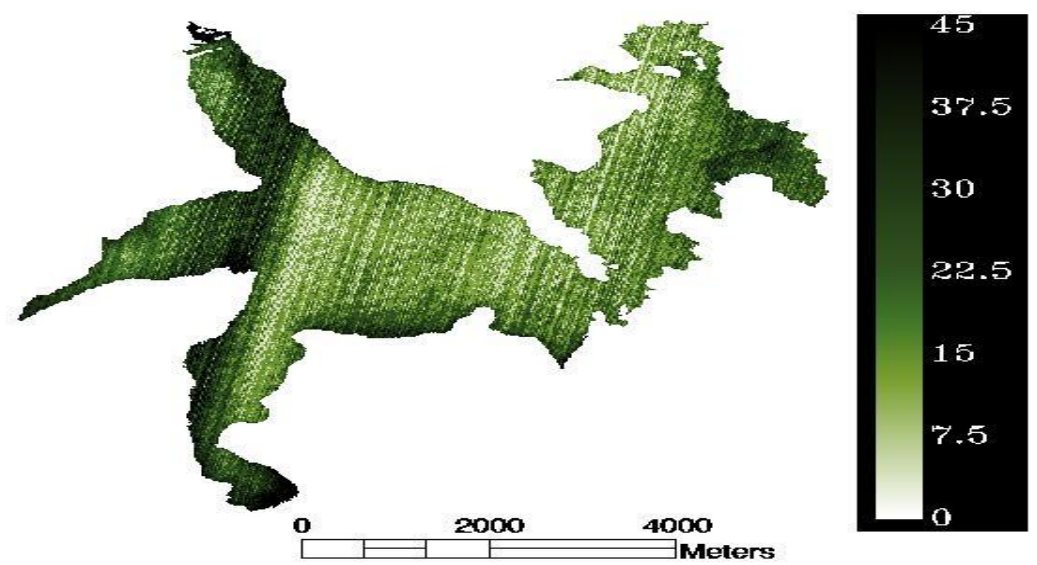

Figura 3. Distribución de la concentración de clorofila-a en Río Tercero.

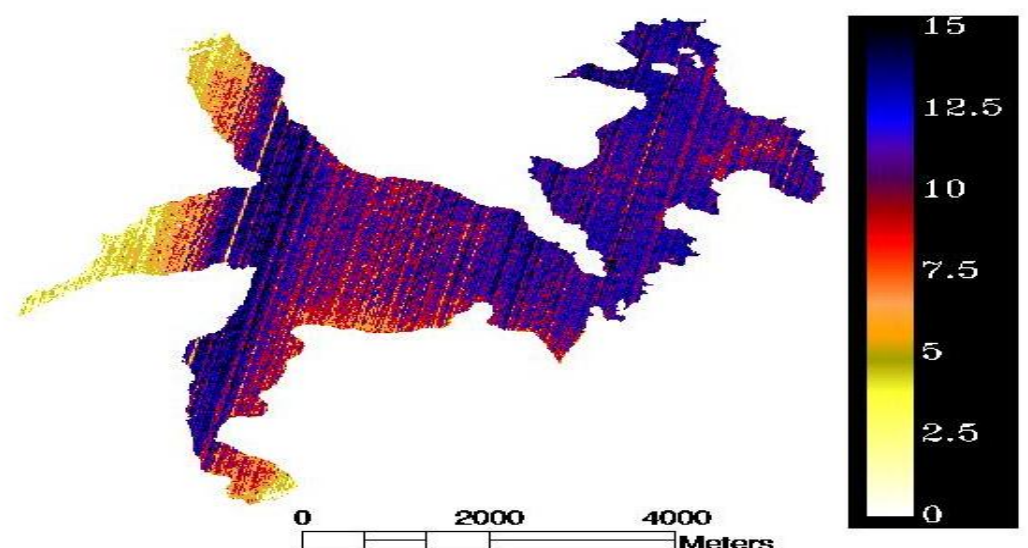

Figura 4. Distribución de la profundidad máxima de zona fótica en Rio Tercero.

Las respuestas estimadas para los modelos de regresión creados fueron aplicadas sobre la máscara del embalse Río Tercero, generada a partir del procesamiento de la imagen CBERS2B en la zona de estudio. De esta manera, se logró mapear la concentración de clorofila-a y el límite de la zona fótica en toda la superficie del embalse Río Tercero (Figura 3 y 4). La franja o línea blanca que se observa en el extremo oeste del mapa de distribución de profundidad máxima de zona fótica, fueron producto de una anomalía radiométrica de la banda 4 del satélite CBERS-2B (Figura 4). Dentro de la evaluación del comportamiento espacial de la cl-a y z-fót en el embalse Río Tercero, y usando teledetección y análisis estadístico, conseguimos relacionar los datos obtenidos en campo con valores de reflectancia provistos por imágenes satelitales. De esta manera se generó una información temática referida a la distribución de los parámetros en toda la superficie del embalse Río Tercero.

A través de los mapas de distribución, podemos observar que existe una correlación negativa entre cl-a y z-fot. No obstante, en las zonas de entrada de ríos, donde se observa con más claridad la relación negativa entre ambas variables, la baja transparencia del agua no estaría dada por una alta concentración de algas, sino por altas cantidades de sólidos en suspensión que descargan en las aguas de los ríos de la cuenca del reservorio en estudio. Esto es demostrado con el ACP, donde se observa una ausencia de correlación entre este par de variables. Si bien las anomalías radiométricas fueron frecuentes en las bandas del satélite CBERS-2B, este sensor resultó un buen instrumento en lo que respecta a la resolución 
espacial, cuando comparamos con otros instrumentos de sensoramiento remoto, como los de la serie LANDSAT.

En la actualidad son conocidas integraciones entre sensores remotos (Santos et al., 2005; Mattews et al., 2010), como también su utilización múltiple (Bentz et al., 2005).

\section{CONCLUSIONES}

A partir de las informaciones obtenidas del embalse Rio Tercero, es posible generar los esfuerzos futuros que deben ser realizados en lo que respecta al manejo y saneamiento del reservatorio. Al mismo tiempo, estas informaciones permiten realizar el HEWS (Sistemas Alerta Temprana de la Salud), para establecer el área de riesgo crítico a la salud pública y animal. En cuanto a la concentración de clorofila-a, se registró un aumento en la concentración de nutrientes, principalmente en fósforo. Se observó un aumento del oxigeno disuelto y el pH no presentó una tendencia particular. Finalmente, fue importante comparar los resultados obtenidos con los conocidos en algunos escenarios brasileros; próximos de la provincia de Córdoba (Rio Tercero), a fin de informar a las autoridades, organizaciones e instituciones públicas y privadas, sobre la situación actual de la calidad del agua en ambos países del Mercosur; así como incitar el monitoramiento y conservación de los embalses acuáticos.

\section{REFERENCIAS}

AMERICAN PUBLIC HEALTH ASSOCIATION - APHA; AMERICAN WATER WORKS ASSOCIATION - AWWA; WATER ENVIRONMETAL FEDERATION - WEF. Standard methods for the examination of water and wastewater. $18^{\text {th }}$ edition. Washington, DC, 2000.

BENTZ, C. M.; POLITANO, A. T.; GENOVEZ, P. Monitoramento ambiental de áreas costeiras e oceânicas com múltiplos sensores orbitais. Revista Brasileira de Cartografia, v. 57, n. 1, p. 43-47, 2005.

BOLtovskoY, A.; FOGGETTA, M. Limnología física del Embalse Rio III. Biología Acuática, v. 7, p. 1-26, 1985.

BREUNIG, F. M.; WACHHOLZ, F.; PEREIRA FILHO, W.; RUDORFF M. de C. Análise das propriedades ópticas da água do reservatório Rodolfo Costa e Silva-Itaara, RS, Brasil, usando dados espectrais. Ambiente \& Água, v. 2, n. 2, p. 88-102, 2007. http://dx.doi.org/10.4136/ambi-agua.28

BRUNKOW, R. F. et al. Monitoramento da qualidade das águas dos reservatórios estado do Paraná, no período de 1999 a 2004. Curitiba: IAP, 2004. 12p.

CESTARI, A. C.; KRUG, T.; NOVO, E. Modelo empírico para a estimativa de concentração da clorofila na zona eufótica em função da concentração de clorofila na superfície. In: SIMPÓSIO BRASILEIRO DE SENSORIAMENTO REMOTO, 8., 1996, Salvador. Anais... São José dos Campos: INPE, 1996. p. 93-98.

CORAZZA, Rosana. Relações entre variáveis espectrais e limnológicas no reservatório da usina hidrelétrica Dona Francisca/RS. 2010. 103 f. Dissertação (Mestrado em Geografia) - Programa de Pós-Graduação em Geografia e Geociências, Universidade Federal de Santa Maria, 2010. 
BONANSEA, M.; LEDESMA, C.; RODRIGUEZ, C.; DELGADO, A. S. R. Concentración de clorofila-a y límite de zona fótica en el embalse Río Tercero (Argentina) utilizando imágenes del satélite CBERS-2B. AmbiAgua, Taubaté, v. 7, n. 3, p. 61-71, 2012. (http://dx.doi.org/10.4136/ambi-agua.847)

DIAS, N. W.; MORAES, E. C.; NOVO, E. M.; MORAES, L.; ARAI, E.; CATELANI, C. S. Caracterização das águas da represa de Paraibuna com o uso de dados hiperespectrais. In: SIMPÓSIO BRASILEIRO DE SENSORIAMENTO REMOTO, 13., 2007, Florianópolis. Anais... São José dos Campos: INPE, 2007. p. 3335-3342.

ENVIRONMENTAL SYSTEMS RESEARCH INSTITUTE - ESRI. ENVI Versión 3.5: programa de análisis y procesamiento de imágenes satelitales. Redlands, 2001.

FELIX, I. M. Monitoramento da qualidade da água utilizando-se modelos empíricos obtidos a partir de sensoriamento remoto Reservatório de Barra Bonita - SP. In: SIMPÓSIO BRASILEIRO DE SENSORIAMENTO REMOTO, 7., 1993, Curitiba. Anais... São José dos Campos: INPE, 1993. p. 119-127.

GONZALEZ, O. S.; ALMEIDA, C. A.; QUINTAR, S.; MALLEA, M. A.; GONZALEZ, P. S. Application of multivariate statistical techniques to evaluate organic pollution on a river in Argentina. Ambiente \& Água, v. 6, n. 3, p. 27-42, 2011. http://dx.doi.org/10.4136/ambi-agua.696

LINO, C. O.; LIMA, M. G. R.; HUBSCHER, G. L. CBERS - An international space cooperation program. Acta Astronáutica, v. 47, n. 2/9, p. 559-564, 2000. http://dx.doi.org/10.1016/S0094-5765(00)00094-1

MARGALEF, R. Teoría de los sistemas ecológicos. Barcelona: Alfa Omega, 2002.

MARIAZZI, A. A.; DONADELLI, J. P.; ARENAS, M. DI SIERVI; BONETTO, C. Impact of a nuclear power plant on water quality of Embalse del Río Tercero reservoir (Córdoba, Argentina). Hidrobiología, v. 246, n. 2, p. 129-140, 1992. http://dx.doi.org/10.1007/BF00014700

MARTINI, L. C.; MATTOS, D. S.; BARBOSA, D. F. P.; RECH, A. I. B. Uso de sensoriamento remoto orbital para avaliação da distribuição espacial de Clorofila_a na Lagoa da Conceição - Florianópolis, SC. Engenharia Sanitária e Ambiental, v. 11, n. 4, p. 318-324, 2006. http://dx.doi.org/10.1590/S1413-41522006000400004

MATTEWS, M. W.; BERNARD, S.; WINTER, K. Remote sensing of cyanobacteriadominant alga blooms and water quality parameters in Zeekoevlei, a small by hypertrophic lake, using MERIS. Remote sensing of environment, v. 114, n. 9, p. 2070-2087, 2010. http://dx.doi.org/10.1016/j.rse.2010.04.013

NOVO, E. M. L. de M. Sensoriamento remoto: princípios e aplicações. 2. ed. São Paulo: Edgard Blucher, 1998. 308p.

PEREIRA FILHO, W. et al. Relação entre clorofila a com perfil espectral e imagem de satélite no reservatório Passo Real - RS. In: SIMPÓSIO BRASILEIRO DE SENSORIAMENTO REMOTO, 15., 2011, Curitiba. Anais... São José dos Campos: INPE, 2011. p. 5433-5440.

RODRÍGUEZ, C. et al. Estudio bacteriológico y químico del embalse Río Tercero (Córdoba). Revista Ciencia Veterinaria, v. 27, p. 3-8, 1997.

RODRÍGUEZ, C. M.; BONANSEA M.; BONATTO, F.; REYNOSO, V.; PROSPERI, C. MANCINI, M. et al. Remote sensing-GIS to predict on the risk of eutrophication in aquatic systems. IN: THE INTERNATIONAL TRADE EVENT AND CONFERENCE FOR EHEALTH, TELEMEDICINE AND HEALTH ICT - Med-e-Tel, 12., 2006, Luxembourg. Proceedings... Luxembourg: Luxexpo, 2006. p. 343-345. 
BONANSEA, M.; LEDESMA, C.; RODRIGUEZ, C.; DELGADO, A. S. R. Concentración de clorofila-a y límite de zona fótica en el embalse Río Tercero (Argentina) utilizando imágenes del satélite CBERS-2B. AmbiAgua, Taubaté, v. 7, n. 3, p. 61-71, 2012. (http://dx.doi.org/10.4136/ambi-agua.847)

RUDORFF, C. M.; NOVO, E. M. L. M.; GALVÃO, L. S.; PEREIRA FILHO, W. Análise derivativa de dados hiperespectrais medidos em nível de campo e orbital para caracterizar a composição de águas opticamente complexas na Amazônia. Acta Amazônica, v. 37, n. 2, p. 269-280, 2007. http://dx.doi.org/10.1590/S004459672007000200014

RYDING, S.; RAST, W. El control de la eutrofización en lagos y pantanos. Madrid: Pirámide, 1992.

SANTOS, J. W. M. C.; DUBREUIL, V. Estimativa da distribuição temporo-espacial de material em suspensão nas águas do reservatório de Manso-MT a partir de imagens Landsat e dados de campo. In: SIMPÓSIO BRASILEIRO DE SENSORIAMENTO REMOTO, 14., 2009, Natal. Anais... São José dos Campos: INPE, 2009. p. 5421-5428.

SANTOS, J. R. dos; MALDONADO, F. D.; ALENCASTRO GRAÇA, P. M. L. Integração de imagens LANDSAT+CBERS-2B para detecção de mudanças em área da Amazônia sob domínio da floresta de transição. Revista Brasileira de Cartografia, v. 57, n. 01, p. 15-27, 2005.

SASS, G.; CREED, I.; BAYLEY, S. E.; DEVITO, K. Understanding variation in trophic status of lakes on the Boreal Plain: a 20 year retrospective using Landsat TM imagery.

Remote Sensing of Environment, v. 109, n. 2, p. 127-141, 2007. http://dx.doi.org/10.1016/j.rse.2006.12.010

VINCENT, R.; QIN, X.; MCKAY, R.; MINER, J.; CZAJKOWSKI, K.; SAVINO, J. et al. Phycocyanin detection from LANDSAT TM data for mapping cyanobacterial blooms in Lake Erie. Remote Sensing of Environment, v. 89, n. 3, p. 381-392, 2004. http://dx.doi.org/10.1016/j.rse.2003.10.014

TODT, V.; RUBERT, C.; SILVA, J. D. S.; FORMAGGIO, A. R.; SHIMABUKURO, Y. E. Classificador adaptativo para o reconhecimento de alvos em imagens. Revista Brasileira de Cartografia, v. 58, n. 3, p. 293-305, 2006.

TUNDISI, J. G. Água no século XXI: enfrentando a escassez. 2. ed. São Carlos: RiMA, 2005. 248p.

TUNDISI, J. G.; TUNDISI, T. M.; ROCHA, O. Ecossistemas de águas interiores. In: REBOUÇAS, A. C.; BRAGA, B.; TUNDISI, J. G. (Orgs.). Águas doces no Brasil: capital ecológico, uso e conservação. 3. ed. São Paulo: Escrituras, 2006. p. 161-202.

UNIVERSIDAD NACIONAL DE CÓRDOBA. InfoStat profesional: statistical Software. Córdoba, 2008.

WACHHOLZ, F. Alterações espectrais nas imagens de satélites nos reservatórios das usinas hidrelétricas Caçu e Barra dos Coqueiros - GO. Revista Geonorte, v. 2, n. 4, p. 11701179, 2012. Edição especial.

ZHU, L.; WANG, S.; ZHOU, Y.; YAN, F.; WANG, L. Determination of chlorophyll a concentration changes in Taihu lake, China using multi-temporal MODIS image data. In: GEOSCIENCE AND REMOTE SENSING SYMPOSIUM, 5., 2005, Seoul. Proceedings... [S.1.]: IEEE International, 2005. Vol. 7. p. 4535- 4538. http://dx.doi.org/10.1109/IGARSS.2005.1526674 